\title{
Matrix metalloproteinase- 1 is a crucial bone metastasis factor in a human breast cancer-derived highly invasive cell line
}

\author{
NORITAKA OKUYAMA, AKIHIKO MATSUMINE, RIEKO KOSUGI, \\ HIROKI WAKABAYASHI and ATSUMASA UCHIDA \\ Department of Orthopedic Surgery, Mie University Graduate School of Medicine, Tsu-City, Mie, Japan \\ Received January 19, 2008; Accepted February 25, 2008 \\ DOI: $10.3892 /$ or_00000171
}

\begin{abstract}
Bone metastasis is one of the most severe cancer complications. To analyze the mechanism of bone metastasis, we established highly invasive cell lines from the human breast cancer cell line MDA-MB-231 using an in vitro sequential selection system. The cell lines, MDA-231-S10 and MDA-231-S5, were more invasive and more motile than the parental cell line. Moreover, MDA-231-S10 metastasized to bone more often when inoculated into the arterial circulation of nude mice. MDA-231-S10-bearing nude mice had a significantly poorer prognosis, and their bony metastatic tumors grew more rapidly than those of the mice bearing the parental cell line (MDA-231-P). Given that a high expression of matrix metalloproteinase (MMP) is reported to be associated with cancer invasiveness, we examined MMP expression. Our results showed that the expression of MMP-3, -5, -7, -9, -13 and -14 was decreased on Multiplex real-time quantitative RT-PCR analysis in the two new cell lines. The zymographic analysis showed no MMP-2 activity and a decreased MMP-9 activity in MDA-231-S10. However, the expression of MMP-1 in MDA-231-S10 was increased. We therefore concluded that MMP-1 plays a crucial role in breast cancer bone metastasis. Furthermore, our MDA-231derived cell lines are useful analytical models of MMP-1associated breast cancer bone metastasis.
\end{abstract}

\section{Introduction}

Bone metastasis frequently occurs in advanced breast cancer patients. Among patients with metastatic breast cancers, 70\% have skeletal involvement (1). It has also been observed that patients with predominantly bone metastases have a worse prognosis than those with soft tissue metastases, because the bone metastases are more resistant to endocrine therapy and

Correspondence to: Dr Aihiko Matsumine, Department of Orthopedic Surgery, Mie University Graduate School of Medicine, 2-174, Edobashi, Tsu-city, Mie 514-8507, Japan

E-mail:matsumin@clin.medic.mie-u.ac.jp

Key words: bone metastasis, breast cancer, invasion, matrix metalloproteinase-1, in vitro selection system chemotherapy than metastases to non-bone organs $(2,3)$. Bone metastases cause severe complications, such as intractable bone pain, pathological fractures and hypercalcemia, which can have a largely negative impact on the patient quality of life. Therefore, controlling bone metastases is of major clinical importance.

The mechanisms of breast cancer bone metastasis remain poorly understood. In part, this is due to the lack of a suitable animal bone metastasis experimental model. To be able to analyze the mechanism of bone metastasis, a human cancer cell line that frequently metastasizes to bone is needed. In 1973, MDA-MB-231, a human breast cancer cell line, was established by Cailleau et al (4). Since it metastasizes to bone when injected into the arterial circulation of nude mice (5), we postulated that this cell line may contain subpopulations of cells that have differing potentials of metastasizing to bone. Therefore, we attempted to isolate an MDA-MB-231-derived highly invasive breast cancer cell line using a matrigel invasion chamber.

Several in vivo and in vitro experimental methods have been developed that enable one to isolate subpopulations of cancer cells with a high metastatic potential to a specific organ (6-11). However, these in vivo selection systems are timeconsuming and expensive. In contrast, our method which uses the matrigel invasion chamber does not require a large investment of time and cost to isolate a cell line that metastasizes to bone. Cancer cells must migrate by crossing multiple extracellular matrix (ECM) barriers, such as the epithelial basement membrane and interstitial stroma, and then enter the blood vessels or lymphatics. Finally, these cells extravasate to form metastatic deposits at a distant site. The cell subpopulation that is isolated using a matrigel invasion chamber is thought to have the specific characteristics that allow the cells to migrate easily by crossing the ECM barrier and then form metastasized foci.

In the present study, we isolated highly invasive cell lines, MDA-231-S5 and MDA-231-S10, from MDA-MB-231 using an in vitro selection system and analyzed the new cell lines by comparing them to the parental cell line (MDA-231-P).

\section{Materials and methods}

Cell line and culture. MDA-MB-231 was kindly provided by Dr T. Yoneda (Osaka University, Graduate School of Dentistry, Osaka). Cells were cultured to subconfluence in Dulbecco's 
modified Eagle's medium (DMEM) supplemented with $10 \%$ fetal bovine serum (FBS, Invitrogen Corp., Carlsbad, CA, USA) at $37^{\circ} \mathrm{C}$ and $5 \% \mathrm{CO}_{2} / 95 \%$ air atmosphere.

Isolation of the highly invasive cell line. To isolate the highly invasive cell line, we used culture insert filters (BectonDickinson, Franklin Lakes, NJ, USA) with $8-\mu \mathrm{m}$ pores, which were precoated with $11 \mu \mathrm{g}$ of matrigel (Becton-Dickinson) on the upper surface and dried at room temperature overnight. The matrigel was diluted to $0.4 \mu \mathrm{g} / \mathrm{ml}$ with icecooled phosphate-buffered saline (PBS) before coating. The upper compartment of the chamber was filled with serumfree medium and the lower one with DMEM containing $10 \%$ FBS. The amount of medium was adjusted so that it was the same height in the two chambers. Cells were suspended in serum-free DMEM and seeded on filters of the culture insert at a density of $5 \times 10^{5}$ cells/chamber. They were incubated at $37^{\circ} \mathrm{C}$ for $24 \mathrm{~h}$. Invading cells that appeared on the lower surface of the filters were collected using the EDTA/trypsin technique and cultured in the medium containing $10 \%$ FBS. The medium was changed every 2 or 3 days.

Once the collected cells were grown to subconfluence, they were again seeded on filters precoated with matrigel at the same density. This was repeated 10 times. We named cell lines using the prefix $S$ (selection) followed by the number of times the cells had been passed through the matrigel. The cells that invaded the matrigel 5 (MDA-231-S5) and 10 times (MDA-231-S10) were analyzed by comparing them to the parental cell line (MDA-231-P). Two days after seeding on a 60-mm dish, the appearance of each cell line was assessed and photographed using an Olympus IX 70.

Cell growth curve analysis. Once each cell line was grown to subconfluence, the cells were re-seeded (day 0) in a 60-mm dish at a density of $1 \times 10^{5} /$ dish in DMEM supplemented with $10 \%$ FBS. The medium was changed every 2 or 3 days. When harvested, the cells were trypsinized and counted 3 times with a hemocytometer (Nitirin, Tokyo) under a phasecontrast light scope. Three dishes for each cell line were counted every other day. The average numbers were plotted and the results were analyzed statistically (post-hoc test).

Assessment of bone metastases. Subconfluent cells were harvested using $0.25 \%$ trypsin and $0.05 \%$ EDTA after being cultured for $24 \mathrm{~h}$ in DMEM supplemented with $10 \%$ FBS, and suspended in PBS at a density of $1 \times 10^{5}$ cells $/ 0.1 \mathrm{ml}$ PBS. The cells were then injected slowly into the left cardiac ventricles of 5-week-old female nude mice (BALB/cA-Jcl-nu, CLEA Japan) under deep anesthesia with pentobarbital $(0.05 \mathrm{mg} / \mathrm{g})$. The nude mice were sacrificed 3 weeks after the cardiac injection of the cancer cells and radiographs were taken. The supine mice were laid against the film (Fuji medical X-ray film RX-U, Fuji Film, Japan) and exposed to X-rays at $60 \mathrm{kV}$ for $6 \mathrm{sec}$ using an X-ray exposure system (ED-125L, Shimadzu, Japan). The film was developed using Cepros M2 (Fuji Film, Japan). Osteolytic bone metastases in the upper and lower extremities were assessed based on these radiographs. Using the Lumina Vision image analysis system (Mitani, Japan) the radiographs were analyzed to determine the number and size of the areas of osteolytic bone resorption. All of the procedures were performed according to protocols approved by the committee of animal research of Mie University.

Matrigel invasion assay. Matrigel invasion assay was carried out using filters precoated with matrigel. Cells were suspended in serum-free DMEM and seeded on filters precoated with matrigel $(11 \mu \mathrm{g} /$ filter $)$ at a density of $5 \times 10^{5} /$ chamber. The lower compartment of the chamber was filled with DMEM containing $10 \%$ FBS. The amount of medium was adjusted to the same height in the two chambers. The cells were allowed to migrate for $24 \mathrm{~h}$ at $37^{\circ} \mathrm{C}$ in a humidified atmosphere containing $5 \% \mathrm{CO}_{2}$. The cells on the upper side of the filters were removed mechanically. The filters were fixed in $70 \%$ ethanol. The cells that had migrated to the lower surface of the filters were stained with $0.4 \%$ trypan blue and counted using a phase-contrast light microscope. The results were statistically analyzed. Four chambers were used for this assay, and 5 areas in each chamber were investigated.

Phagokinetic track assay. A phagokinetic track assay was performed to quantitatively analyze cell motility. Matrigel was diluted with ice-cooled PBS to $10 \mu \mathrm{g} / \mathrm{ml}$ for the purpose of coating. Coverslips were immersed in the diluted matrigel and incubated at $37^{\circ} \mathrm{C}$ for $1 \mathrm{~h}$. Colloidal gold suspension was prepared by adding $33 \mathrm{ml}$ distilled water and $18 \mathrm{ml} \mathrm{Na}_{2} \mathrm{CO}_{3}$ (36.5 mM) to $5.4 \mathrm{ml} \mathrm{AuHCl} 4$ (14.5 mM). The mixture was heated to $100^{\circ} \mathrm{C}$ and $5.4 \mathrm{ml}$ of $0.1 \%$ formaldehyde solution was added. The coverslips were placed in dishes and the hot gold particle suspension was layered on top. The following day, the gold particle-coated coverslips were sterilized by exposure to UV light for $10 \mathrm{~min}$. The coverslips were washed twice with PBS to remove any unattached gold particles and placed in 35-mm dishes. Two thousand cells, suspended in DMEM supplemented with $10 \% \mathrm{FBS}, 100 \mathrm{IU} / \mathrm{ml}$ of penicillin and $100 \mu \mathrm{g} / \mathrm{ml}$ of streptomycin, were plated in the dishes and incubated for $12 \mathrm{~h}$. The phagokinetic tracks were observed on light microscopy. The images were imported into the computer, and the area of the phagokinetic tracks was analyzed using the Lumina Vision image analysis system. The result was statistically analyzed. Three dishes were used for this assay, and 5 tracks were observed in each dish.

Zymographic analysis. The gelatinase activity of the conditioned medium was tested by zymography using sodium dodecyl sulfate polyacrylamide gel electrophoresis (SDS-PAGE) containing $1 \mathrm{mg} / \mathrm{ml}$ gelatin.

A total of $1 \times 10^{6}$ cells suspended in DMEM supplemented with $10 \%$ FBS was seeded on $60-\mathrm{mm}$ plastic dishes at $37^{\circ} \mathrm{C}$. The following day, the media were changed to $2 \mathrm{ml}$ of serumfree medium and incubated at $37^{\circ} \mathrm{C}$ for $24 \mathrm{~h}$. The supernatant of the conditioned medium was collected and centrifuged to remove cell debris before further use. The conditioned medium from the MDA-231-derived cell lines was mixed with a nonreducing sample buffer $(0.3 \mathrm{M}$ Tris- $\mathrm{HCl}, \mathrm{pH} 6.8,12 \%$ SDS and $0.00012 \%$ bromophenol blue) at a ratio of $1: 5$ and incubated at room temperature for $30 \mathrm{~min}$. Then the samples were electrophoresed on $10 \%$ polyacrylamide gel containing gelatin (Sigma-Aldrich Japan, Tokyo) $(1 \mathrm{mg} / \mathrm{ml})$ in the running gel at a constant $50 \mathrm{~mA}$. The sample volumes were strictly 

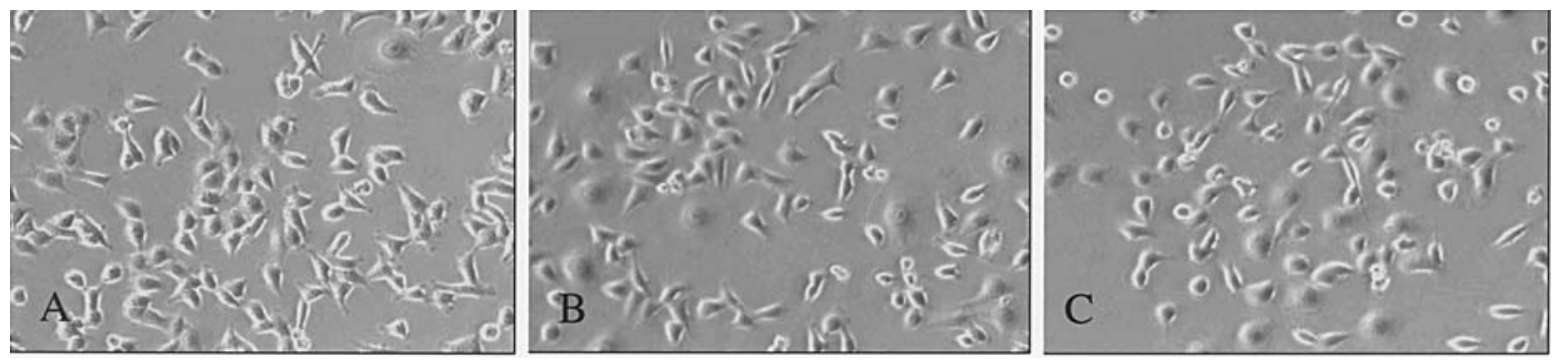

Figure 1. Morphological appearance of parental and newly established cell lines. No morphological differences were noted in the appearance of MDA-231-P (A), MDA-231-S5 (B) and MDA-231-S10 (C) when cultured on the plastic dishes.

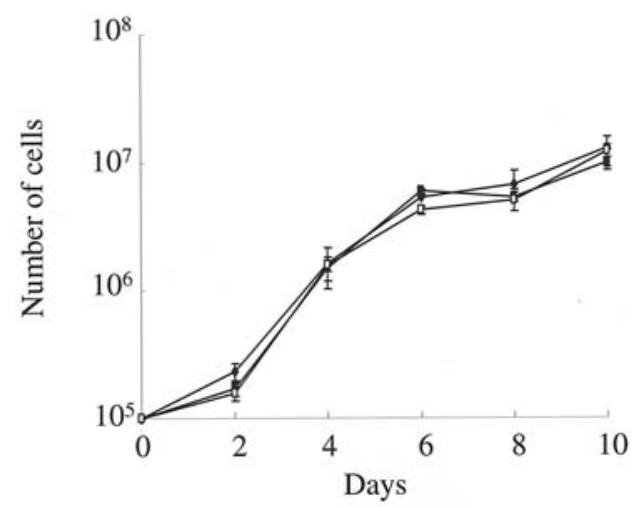

Figure 2. Growth rates of parental and newly established cell lines. Cells were seeded on day 0 and counted every 2 days. No difference in the cell growth between the 3 cell lines of MDA-231-P (॰), MDA-231-S5 (- $)$ and MDA-231-S10 ( $\square$ ) existed. Values represent means \pm SD ( $n=3$ per group).

controlled to be the same $(50 \mu \mathrm{l})$. After electrophoresis, the gel was rinsed three times with washing buffer $(10 \mathrm{mM}$ Tris$\mathrm{HCl}, \mathrm{pH} 7.5$ and $2.5 \%$ Triton X-100) at room temperature for $30 \mathrm{~min}$ to remove the SDS. After being washed twice with the metalloproteinase buffer for $30 \mathrm{~min}$, the gel was incubated with this buffer $(50 \mathrm{mM}$ Tris- $\mathrm{HCl}, \mathrm{pH} 7.5,150 \mathrm{mM} \mathrm{NaCl}, 10$ $\mathrm{mM} \mathrm{CaCl}$ and $0.05 \% \mathrm{NaN}_{3}$ ) at $37^{\circ} \mathrm{C}$ for $24 \mathrm{~h}$. It was then stained with $0.1 \%$ Coomassie brilliant blue staining solution [0.1\% Coomassie brilliant blue 250-R (Sigma-Aldrich Japan), $10 \%$ acetic acid and $10 \%$ isopropanol] for $30 \mathrm{~min}$ and destained in $10 \%$ acetic acid and $30 \%$ methanol. This assay was carried out three times.

Analysis of PTH-rP production. The parathyroid-related protein (PTH-rP) concentrations in the cell culture supernatant of each MDA-231-derived cell line were analyzed using a competitive enzyme immunoassay kit (Peninsula Laboratories, San Carlos, CA, USA). The assay was performed according to the manufacturer's protocol. The supernatant in 4 dishes for each cell line was observed. The result was statistically analyzed using the Kruskal-Wallis test. This assay was carried out twice.

RNA extraction and cDNA synthesis. The total RNA from the subconfluent cells grown in plastic dishes was extracted using an mRNA purification kit (Quick Prep Micro, Amersham Pharmacia Biotech), according to the manufacturer's protocol. The RNA was reverse transcribed using an oligo (dT) primer according to the manufacturer's protocol (SuperScript firststrand synthesis system for RT-PCR, Invitrogen). The cDNA was diluted to twice the original volume and then stored at $-80^{\circ} \mathrm{C}$.

Multiplex real-time quantitative RT-PCR analysis. The matrix metalloproteinase (MMPs) expression was measured by realtime quantitative RT-PCR, based on the Taq man methodology, using the ABI PRISM 7000 sequence detection system (Applied Biosystems Japan, Tokyo). MMP-1 (collagenase-1), MMP-3 (stromelysin-1), MMP-7 (matrilysin), MMP-9 (gelatinase B), MMP-13 (collagenase-3) and MMP-14 (MT1MMP) were investigated. All of the reagents were obtained from Applied Biosystems. The PCR mixture consisted of $25 \mu 1$ of Taq man universal master mix, $2.5 \mu 1$ of assay-ondemand gene expression assay mix and $22.5 \mu 1$ of cDNA diluted in distilled water. The PCR reactions were carried out in a 96-well microtitre plate, using the procedure: 1 cycle at $50^{\circ} \mathrm{C}$ for $2 \mathrm{~min}, 1$ cycle at $95^{\circ} \mathrm{C}$ for $10 \mathrm{~min}$ and 50 cycles at $95^{\circ} \mathrm{C}$ for $15 \mathrm{sec}$ and $60^{\circ} \mathrm{C}$ for $1 \mathrm{~min}$. The relative gene expression levels were calculated using standard curves generated by serial dilutions of cDNA obtained from MDA231-P. Using SDS software (Version 1.0), the relative expression amounts of the samples were calculated compared to the expression levels determined by the standard curve. The expression levels of the housekeeping gene, $\beta$-actin, were quantitated in the same way. The expression levels of each gene and sample were divided by the $\beta$-actin expression level. All mRNA levels were determined in relation to MDA-231-P. All of the samples were analyzed in triplicate.

\section{Results}

Morphology and cell proliferation. After the establishment of the two MDA-231-derived cell lines, we investigated whether any morphological differences between the cell lines existed. No morphological differences were noted among MDA-231-P, MDA-231-S5 and MDA-231-S10 when they were cultured on the plastic dishes (Fig. 1). The growth rates were not statistically different between the cell lines (Fig. 2).

Survival of MDA-231-derived cell line bearing nude mice. To evaluate the biological aggressiveness of our established cell lines, we used the heart injection method and observed the survival rates of nude mice bearing our established MDA231-derived cell line, MDA-231-S10, and those bearing the MDA-231-P cell line. 


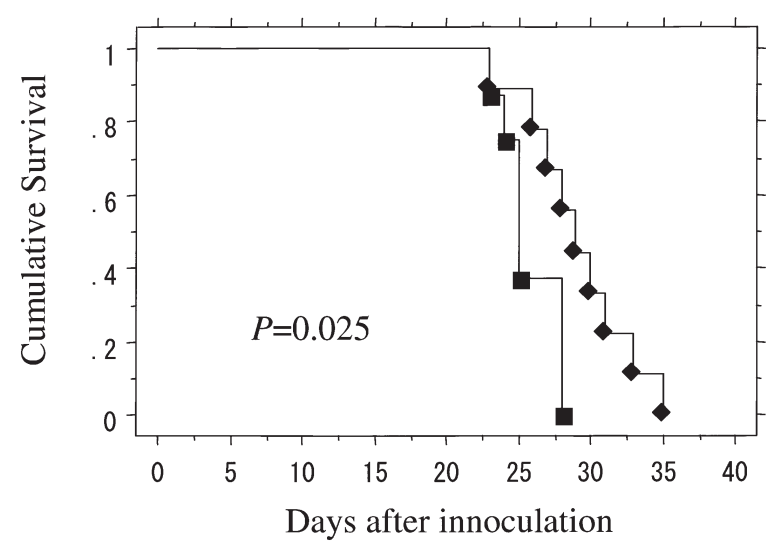

Figure 3. Kaplan-Meier survival analysis of MDA-231-derived cell line bearing nude mice. Cells $\left(1 \times 10^{5}\right)$ suspended in $0.1 \mathrm{ml}$ PBS were injected into the left cardiac ventricles of anesthetized 5-week-old female nude mice. The average survival of MDA-231-P-bearing nude mice was 29 days, while that of MDA-231-S10-bearing nude mice was 26 days. The Kaplan-Meier survival analysis showed a lower survival in MDA-231-S10-bearing nude mice than in the MDA-231-P-bearing nude mice ( $\mathrm{P}=0.025)$. [MDA-231-P ( $), \mathrm{n}=9$ and MDA-231-S10 (घ), n=8].

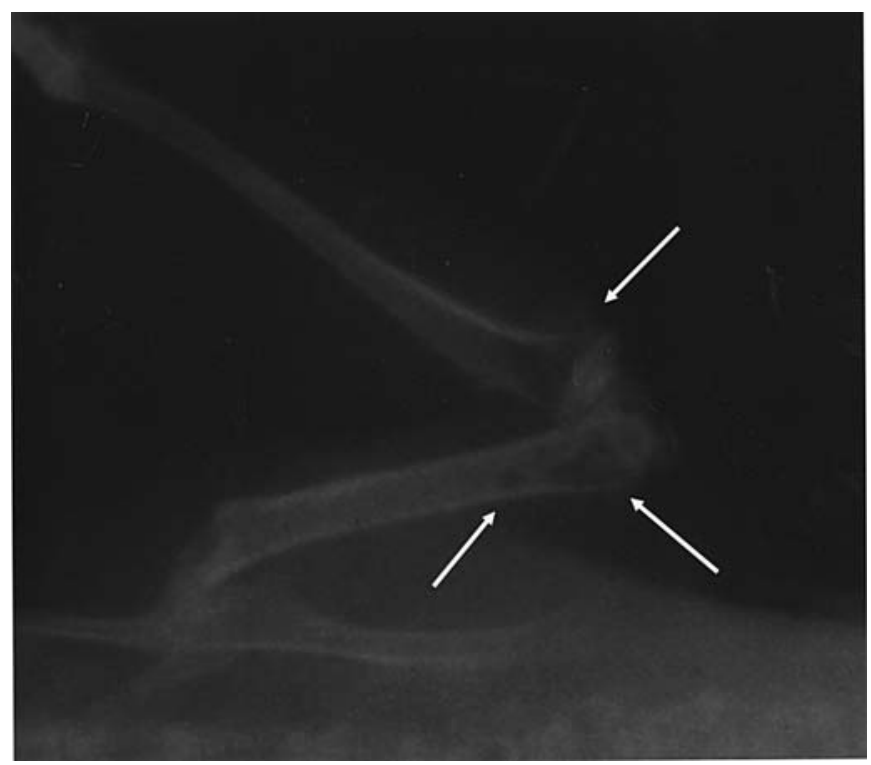

Figure 4. Bone metastases of an MDA-231-S10-bearing nude mouse. The radiograph shows the left hind limb of an MDA-231-S10-bearing nude mouse. The arrows indicate osteolytic bone metastases. Three osteolytic bone metastases are clearly shown.

The mice died 23-35 days after inoculation. The average survival of the MDA-231-P-bearing nude mice was 29 days, and the average survival of the MDA-231-S10-bearing nude mice was $\sim 26$ days. Survival rate analysis based on the KaplanMeier method, showed that the survival of MDA-231-S10bearing nude mice was significantly shorter than that of the MDA-231-P bearing nude mice ( $\mathrm{P}=0.025)$ (Fig. 3).

Bony metastatic potential of our established MDA-231derived cell line. Since we had postulated that our established cell lines would have a high metastatic potential, we compared their bony metastatic potential by using the intracardiac

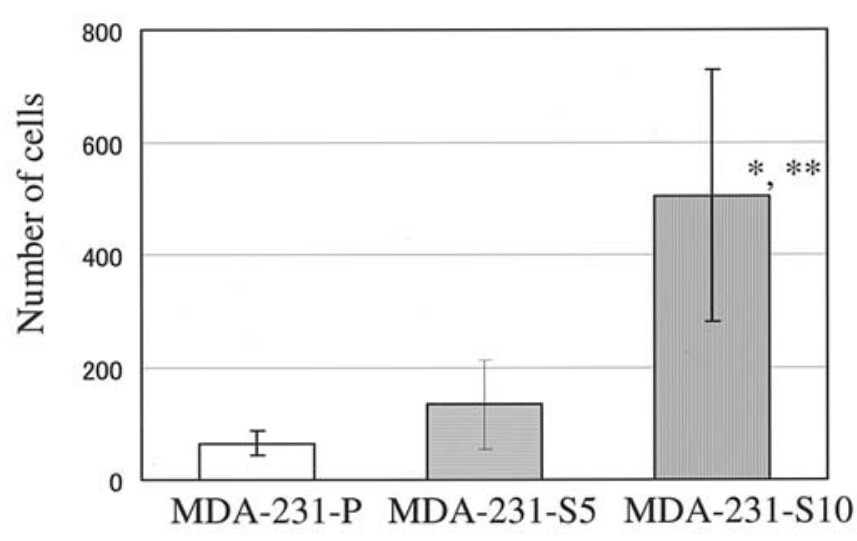

Figure 5. Matrigel invasion assay of parental and newly established cell lines. The matrigel invasion assay was carried out using filters of the culture insert precoated with matrigel. Cells were suspended in serum-free DMEM and seeded on filters precoated with matrigel at a density of $5 \times 10^{5} /$ chamber. The lower compartment of the chamber was filled with DMEM containing $10 \%$ FBS. The cells were incubated for $24 \mathrm{~h}$. Invading cells were stained and counted. MDA-231-S10 was significantly more invasive than MDA-231-S5 and MDA-231-P. Values represent means $\pm \mathrm{SD}$ ( $\mathrm{n}=20$ per group). ${ }^{*}{ }^{* *} \mathrm{P}<0.05$ compared with MDA-231-P and MDA-231-S5, respectively.

inoculation method. Nude mice were sacrificed three weeks after cardiac injections of tumor cells, and radiographs were taken to evaluate bone metastases. Using the Lumina Vision image analysis system the film was analyzed to determine the number and size of the areas with osteolytic bony resorption. The most frequent bone metastasis sites were the distal femur and proximal tibia (Fig. 4). Severe bone metastases causing pathological fractures were observed at these sites We observed no metastases in the skull, ribs, spine and pelvis. In the upper and lower extremities, MDA-231-Pbearing nude mice had $1.8 \pm 1.8$ osteolytic metastases, and MDA-231-S10-bearing nude mice had 3.6 2.4 osteolytic metastases ( $\mathrm{P}=\mathrm{NS}$ for the comparison). The total area of the bone metastases in MDA-231-P-bearing nude mice was $2.29 \pm 2.36 \mathrm{~mm}^{2}$, while in MDA-231-S10-bearing nude mice it was $8.19 \pm 5.34 \mathrm{~mm}^{2}$. The mean area of each metastasis was $0.84 \pm 0.77 \mathrm{~mm}^{2}$ in MDA-231-P-bearing nude mice and $2.28 \pm 0.71 \mathrm{~mm}^{2}$ in MDA-231-S10-bearing nude mice. MDA231-S10-bearing nude mice had statistically larger bone metastases (Table I).

Matrigel invasion assay. To clarify the reason why there was a difference in the bony metastatic capacity between MDA231-P and MDA-231-S10, we initially examined the matrigel invasion capacity of each cell line. The matrigel invasion assay showed that MDA-231-S10 was significantly more invasive than MDA-231-S5 and MDA-231-P. MDA-231-S5 tended to be more invasive than MDA-231-P, but there was no statistically significant difference (Fig. 5).

Phagokinetic track assay. To evaluate the motility of each cell line, we used a phagokinetic track assay (12) (Fig. 6a). MDA-231-S10 was significantly more motile than MDA231-P ( $\mathrm{P}<0.05, \mathrm{n}=15)$, and MDA-231-S5 was significantly more motile than MDA-231-P $(\mathrm{P}<0.05, \mathrm{n}=15)$. Though MDA231-S10 tended to be more motile than MDA-231-S5, the difference was not statistically significant (Fig. 6b). 
$\mathbf{a}$
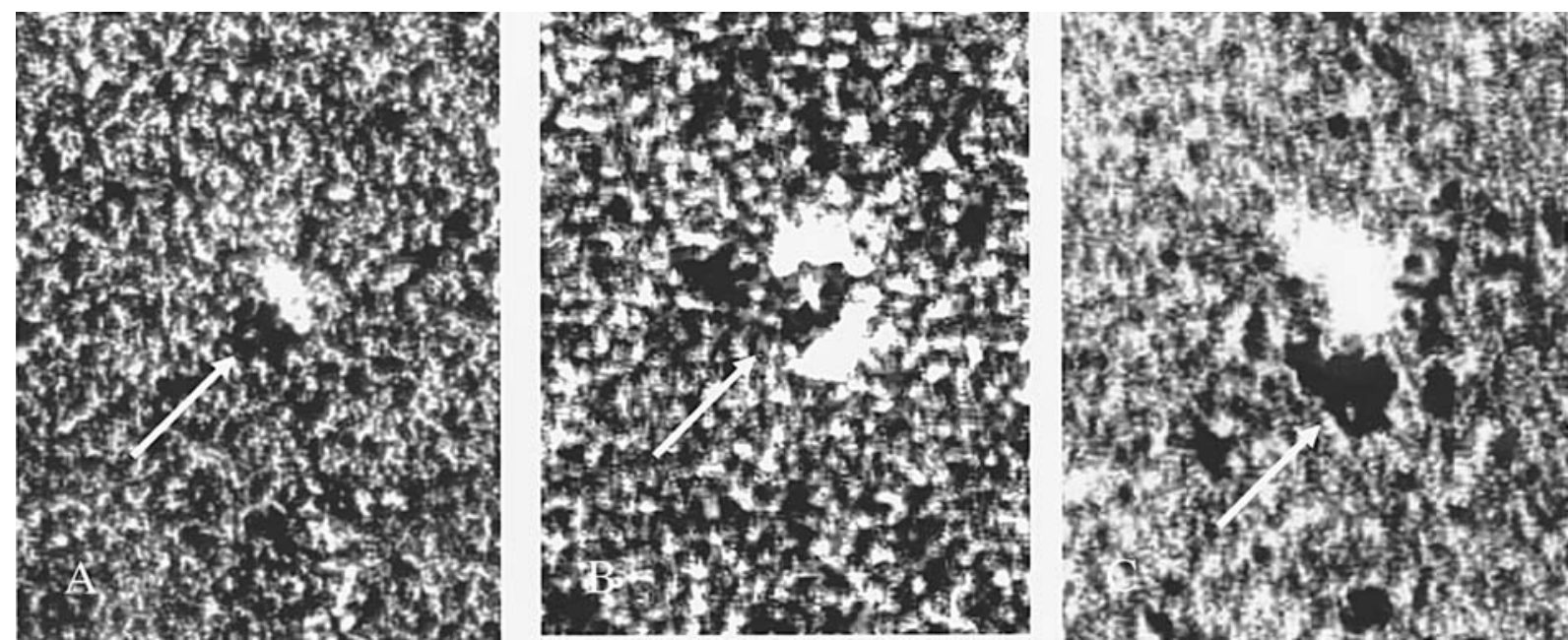

b
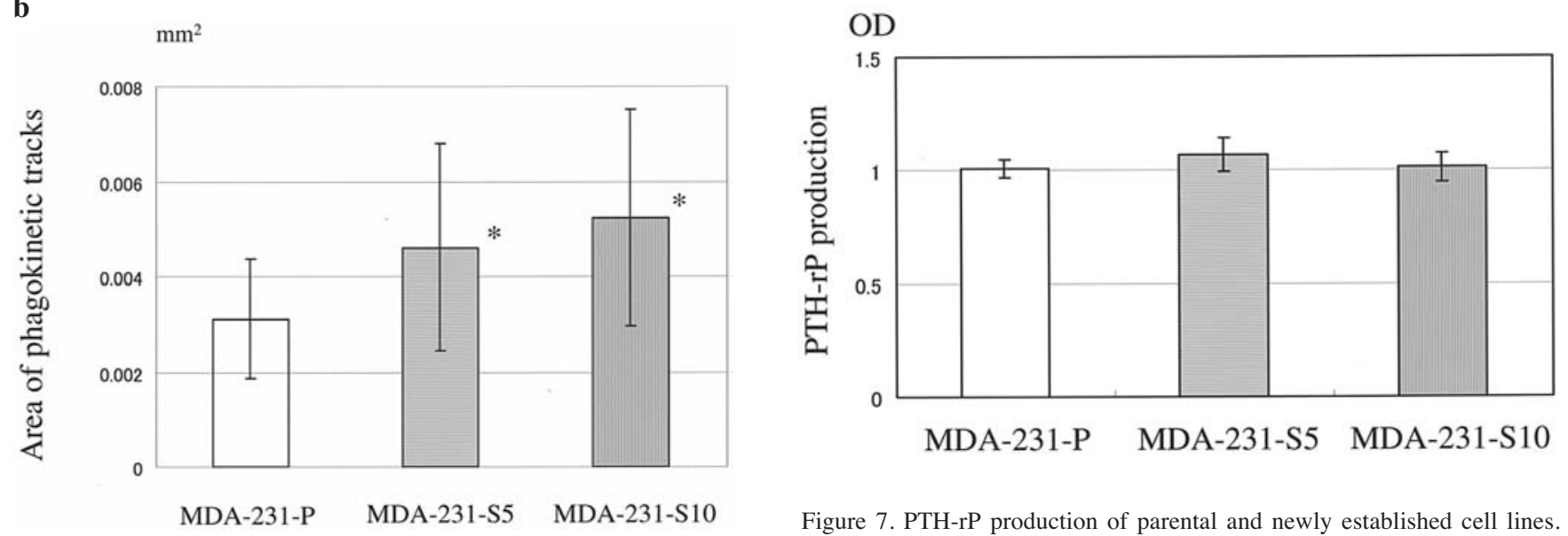

Figure 6. (a) Microscopic findings of phagokinetic tracks of parental and newly established cell lines. A phagokinetic track assay was performed to quantitatively analyze cell motility. A total of 2000 cells suspended in DMEM supplemented with 10\% FBS were plated on the coverslips precoated with hot gold particle suspension and incubated for $12 \mathrm{~h}$. The areas of phagokinetic tracks were investigated with light microscopy. The black spots and arrows indicate cells while the white particle-free area around the cell is the phagokinetic area. (A) MDA-231-P, (B) MDA-231-S5 and (C) MDA231-S10. (b) The phagokinetic track assay of parental and newly established cell lines. The areas of phagokinetic tracks were measured using the Lumina Vision image analysis system. MDA-231-S10 and MDA-231-S5 cells were significantly more motile than MDA-231-P cells. The MDA-231 cells became more motile through our selection process. Values represent means $\pm \mathrm{SD}$ ( $\mathrm{n}=15$ per group). ${ }^{*} \mathrm{P}<0.05$, compared with MDA-231-P.

PTH-rP production. To investigate whether the production of PTH-rP was associated with metastatic properties in our established cell lines, we examined the expression of PTH-rP in each cell line. PTH-rP production was not significantly different among MDA-231-P, MDA-231-S5 and MDA-231S10 (Fig. 7).

Zymographic analysis. Since MMP activities are required when cells migrate through the matrigel barrier, we investigated MMP activities using gelatin zymography. The zymographic analysis showed $90 \mathrm{kDa}$ bands, which represented the activity of MMP-9. Bands of $72 \mathrm{kDa}$ which represented the activity of MMP-2 were not detected. Contrary to our expectations,
Figure 7. PTH-rP production of parental and newly established cell lines. PTH-rP production in MDA-231-P, MDA-231-S5 and MDA-231-S10 was investigated using a competitive enzyme immunoassay. No significant differences among the 3 cell lines existed. Values represent means \pm SD ( $n=4$ per group).

Table I. In vivo bony metastatic analysis.

\begin{tabular}{lccc}
\hline & \multicolumn{2}{c}{ Cell lines } & \\
\cline { 2 - 3 } & MDA-231-P & MDA-231-S10 & P-value \\
\hline $\begin{array}{l}\text { Number of bone } \\
\text { metastases }\end{array}$ & $1.80 \pm 1.80$ & $3.60 \pm 2.40$ & NS \\
$\begin{array}{l}\text { Total area of bone } \\
\text { metastases }^{\mathrm{a}}\end{array}$ & $2.29 \pm 2.36$ & $8.19 \pm 5.34$ & 0.0142 \\
$\begin{array}{l}\text { Mean area of each } \\
\text { bone metastasis }\end{array}$ & $0.84 \pm 0.77$ & $2.28 \pm 0.71$ & 0.0067 \\
\hline
\end{tabular}

In vivo bony metastatic analysis of parental and newly established cell lines. Three weeks after cardiac injection, radiographs were taken. Using the Lumina Vision image analysis system, the film was analyzed to quantify the number and size of the osteolytic bone resorption areas. MDA-231-derived highly invasive cell line bearing nude mice had a significantly larger area of metastasis. Values represent means $\pm \mathrm{SD}(\mathrm{MDA}-231-\mathrm{P}, \mathrm{n}=9$ and MDA-231-S10, $\mathrm{n}=8)$. ${ }^{a} \mathrm{P}<0.05$, compared with MDA-231-P and ${ }^{\mathrm{b}} \mathrm{P}<0.01$, compared with MDA-231-P. NS, not significant. 


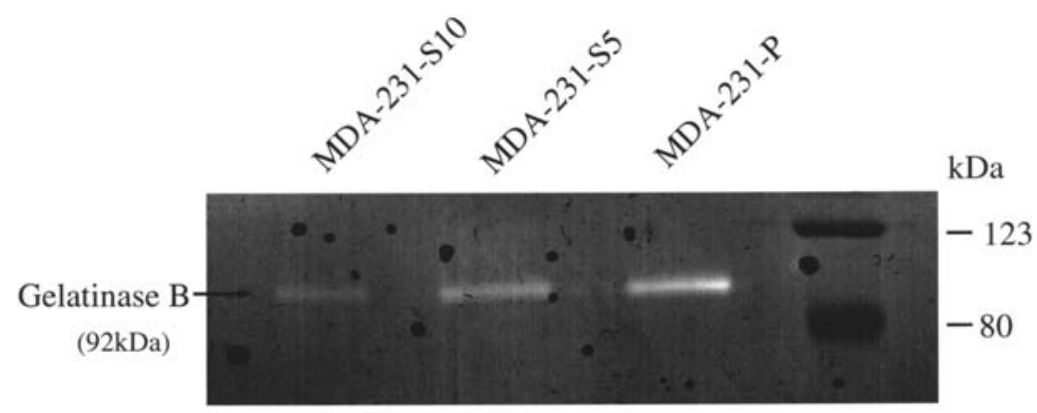

Figure 8. Gelatin zymography of parental and newly established cell lines. Gelatinase activities of a conditioned medium were tested by gelatin zymography using SDS-PAGE containing $1 \mathrm{mg}$ gelatin/ml. The zymographic analysis showed $90 \mathrm{kDa}$ bands which represented the activities of MMP-9. Bands of $72 \mathrm{kDa}$ which represented the activities of MMP-2 were not detected. MDA-231-S10 had the lowest gelatinase activity, while MDA-231-P had the highest.

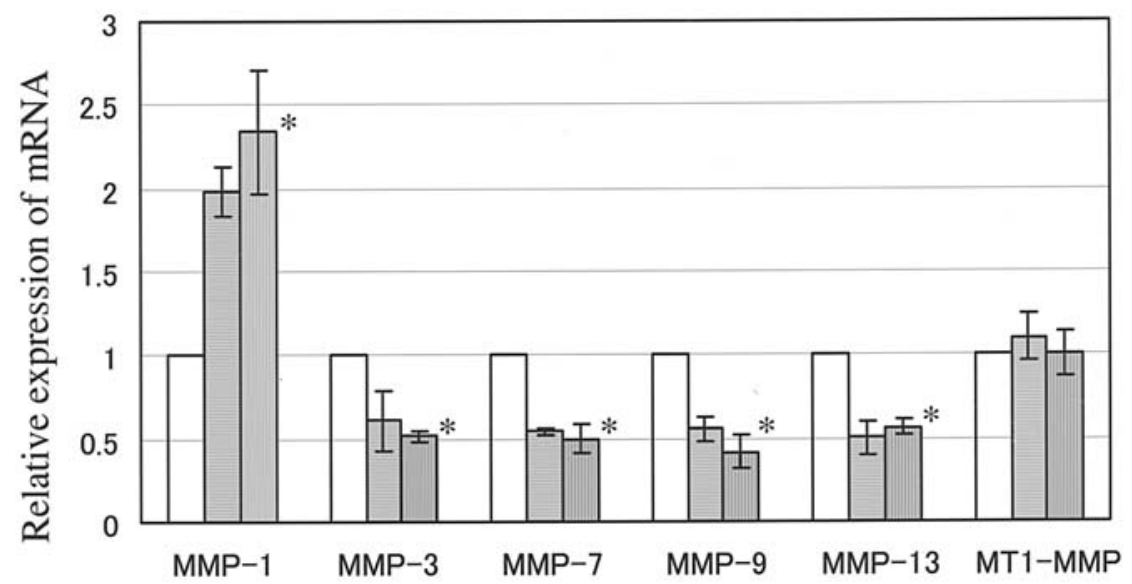

Figure 9. Multiplex real-time quantitative RT-PCR analysis of the MMP expression in parental and newly established cell lines. Multiplex real-time quantitative RT-PCR analysis of mRNA from cells grown in plastic plates was performed to quantitatively analyze MMP expression. MDA-231-S5 (laterally striped bar) and MDA-231-S10 (vertically striped bar) were normalized to MDA-231-P (white bar), which is given a value of 1. MMP-1 expression was increased in the process of selecting subpopulations of cells with a high potential for bony metastases. MDA-231-S10 had an $\sim 2.3$ fold higher MMP-1 expression than MDA-231-P. Contrary to our expectations, MMP-3, -7, -9 and -13 expression was significantly decreased. MT1-MMP expression remained unchanged. Values represent means $\pm \mathrm{SD}$ ( $\mathrm{n}=3$ per group). ${ }^{*} \mathrm{P}<0.05$, compared with MDA-231-P.

MDA-231-P had the highest gelatinase activity, and MDA231-S10 the lowest (Fig. 8).

Matrilysin, MMP-7, activity was also examined using casein zymography with concentrated supernatants. However, caseinolytic activity was not detected (data not shown).

Multiplex real-time quantitative RT-PCR analysis. To clarify MMP participation with respect to the different bony metastatic properties of the three cell lines, we examined the expression of various types of MMP transcripts (Fig. 9). Real-time quantitative RT-PCR analysis showed that MDA-231-S10 and MDA-231-S5 had a significantly higher MMP-1 expression than did MDA-231-P. MDA-231-S10 had an 2.3-fold higher MMP-1 expression than did MDA-231-P. Contrary to our expectations, this analysis also showed that the expression of MMP-3, - 7, -9 and -13 transcripts was decreased by the process of selecting subpopulations with a high bony metastatic potential. MT1-MMP expression remained unchanged. MMP-2 expression was not investigated because it was not detected on gelatin zymography. These results suggest that MMP-1 may play an important role in maintaining the high bony metastatic property of MDA-231-S10.

\section{Discussion}

Advanced multidisciplinary treatment, which includes surgery, chemotherapy and radiotherapy prolong the survival of cancer patients. Nevertheless, cancer metastasis control remains a challenge because the mechanism of cancer metastasis is complicated and poorly understood. Thus, cancer treatment has to deal with the control of primary cancers and management of metastatic lesions.

In particular, bone metastases can cause severe complications, including intractable bone pain, pathological fractures and hypercalcemia, all of which greatly impair the patient quality of life. Animal model research into bone metastasis is starting to play an important role in dealing with this challenge. Several in vivo and in vitro experimental methods have been developed that allow for the isolation of subpopulations of cancer cells that have a high metastatic potential to specific organs (6-11). However, in vivo selection systems are timeconsuming and expensive. In contrast, our method which uses a matrigel invasion chamber to isolate a cell line that metastasizes to bone does not require a large investment of time and money. 
Our established MDA-231-derived cell lines showed no differences in morphology and growth rates in vitro. However, when they were inoculated into the left cardiac ventricles of nude mice, MDA-231-S10 grew more rapidly than MDA-231-P at the sites of bony metastases, although the number of bone metastases did not increase. These results indicate that there was a difference in the bony metastastic potential between the two cell lines, which was likely the result of different growth activity of the tumor cells within the intramedullary bony microenvironment. Studies have shown that a variety of growth factors produced by osteoblasts, including insulin-like growth factors (IGFs), transforming growth factors (TGF) $\alpha$ and $\beta$, fibroblast growth factors and bone morphogenetic proteins are subsequently stored in the bone matrix $(13,14)$. These growth factors are released in their active form into the bone marrow when bone is degraded during osteoclastic bone resorption (15). Therefore, it is possible that the difference in growth seen with the MDA231-P and MDA-231-S10 cell lines may be explained by the two cell lines having different sensitivities to the growth factors released at the metastatic site due to osteoclast-mediated bone resorption.

Furthermore, our established cell lines were more motile and more invasive than the parental cell line. Rho protein and Rho-regulatory proteins are key components that mediate breast cancer motility (16). While we have yet to examine Rho GTPase signaling in our cell lines, such factors may contribute to the difference in motility between MDA-231-P and MDA-231-S10 at bony metastatic sites.

Reports have suggested that the MMPs are involved in the initial step of ECM degradation during the metastatic process (17-23). MMPs have a more complex role than was initially appreciated, in that the MMP-mediated degradation of ECM components may generate inhibitors of angiogenesis, as well as products that stimulate cell migration and/or invasion and release activated cytokines stored in ECM $(24,25)$. To clarify the role of MMPs in our established cell lines with their different bony metastatic potentials, we examined MMP-2, -7 and -9 activities using gelatin and casein zymography, and studied the expression of transcripts of MMP-1, -3, -7, -9, -13 and -14. MDA-231-S10 and MDA231-S5 had a significantly higher MMP-1 expression than MDA-231-P. Kang et al used microarray analysis to show that overexpression of MMP-1 enhances MDA-231 bone metastases (26). In human breast carcinoma, the expression of MMP-1 has been investigated at the primary (27-30) and bony metastatic sites (31). In bone matrix, type I collagen is the major protein, comprising of $\sim 90 \%$ of the organic matrix (32). During cancer dissemination, the bone matrix must be broken down mainly by the interstitial collagenase, MMP-1. Our results suggest that MMP-1 may play an important role in maintaining the high bony metastatic potential in our established cell line, MDA-231-S10. It appears that our in vitro selection system allows for the selection of a cell line with high MMP-1 activity, and is a suitable model for elucidating the MMP-1-related mechanism of bone metastasis.

Contrary to our expectations, our analysis also showed that the expression or activity of transcripts of MMP-3, -7, -9 and -13 decreased in the process of selecting cell subpopulations with a high potential for bony metastases. However, MMP-14
(MT1-MMP) expression remained unchanged. The major components of reconstituted matrigel include: laminin (60\%), type IV collagen (30\%), heparin sulfate proteoglycan (3\%), entactin (1\%) and nidogen (5\%) (33). The type IV collagen component of the basement membrane is thought to be degraded mostly by MMP-2 and -9 . Surprisingly, our results showed that a higher invasive capacity was associated with a lower expression of MMP-9. The reason for this negative correlation is uncertain, though degradation of the matrigel may be performed by proteinases other than MMP-9 by the cells chosen in our selection system. Kawamata et al also reported a decreased expression of MMP-9 in a highly invasive esophageal squamous cell carcinoma line that was isolated by an in vitro selection system similar to ours (34). Their findings are consistent with ours. Furthermore, Farina et al reported that MMP-3 inhibited MDA-231 cell invasion in vitro by a mechanism involving plasminogen degradation to fragments that limit the degradation of laminin, the major structural component of reconstituted matrigel (35). Thus, this report supports our finding that a higher invasive potential was associated with a lower expression of MMP-3.

The survival rate of MDA-231-S10-bearing nude mice was significantly lower than that of MDA-231-P-bearing nude mice. Moreover, MDA-231-S10-bearing nude mice had a markedly cachexic appearance (data not shown). Although at first we suspected the existence of hypercalcemia in MDA231-S10 mice, there was no evidence of hypercalcemia. Unknown factors may have enhanced the progression of cachexia in MDA-231-S10-bearing nude mice, since the reasons for the short survival of MDA-231-S10-bearing nude mice remain uncertain.

Cancer invasiveness and metastatic potential are also determined by the expression levels of certain cytokines. Many researchers have reported that osteoclasts stimulated by cancer cells either directly or indirectly play an important role in increasing bone resorption (36-39). In breast cancer, PTH-rP secreted by cancer cells has been shown to stimulate the formation and resorptive activity of osteoclasts $(17,40,41)$. However, our results showed that PTH-rP production by the MDA-231-S10 was not up-regulated despite an increased bone resorption capacity. These data indicate that the production of PTH-rP is not correlated with the osteolytic bone metastasis in our in vivo animal model. Sanchez-Sweatman et al reported the possibility that metastatic cancer cells degrade bone matrix directly and that this is partially mediated by MMPs (42), which is consistent with our results.

In conclusion, we isolated highly invasive and metastatic cell lines in vitro with a sequential passage method using filters of the culture insert precoated with matrigel. The two cell lines had the same appearance and growth rates, in the plastic dishes, as the parent cell line. When inoculated into the left ventricles of nude mice, the two cell lines metastasized to bone to a greater extent than the parent cell line. The two cell lines had a higher MMP-1 expression than the parent cell line. The results of the present study suggest that MMP-1 may play a crucial role in the formation of bone metastases caused by MDA-231-S10 cells injected into our animal model. Our MDA-231-derived cell lines will become powerful tools in the study of breast cancer bony metastases. 


\section{References}

1. Coleman RE and Rubens RD: The clinical course of bone metastases from breast cancer. Br J Cancer 55: 61-66, 1987.

2. Mouridsen H, Gershanovich M, Sun Y, et al: Superior efficacy of Letrozole versus Tamoxifen as first-line therapy for postmenopausal women with advanced breast cancer: results of phase III study of the international Letrozole breast cancer group. J Clin Oncol 19: 2596-2606, 2001.

3. Mastro LD, Venturini M, Lionetto R, et al: Accelerated-intensified cyclophosphamide, epirubicin and fluorouracil (CEF) compared with standard CEF in metastatic breast cancer patients: results of a multicenter, randomized phase III study of the Italian gruppo oncologico Nord-Ouest-Mammella inter gruppo group. J Clin Oncol 19: 2213-2221, 2001

4. Cailleau R, Yong R, Olive M and Reeves W: Breast tumor cell lines from pleural effusions. J Natl Cancer Inst 53: 661-674, 1974.

5. Yoneda T, Sasaki A and Mundy GR: Osteolytic bone metastasis in breast cancer. Breast Cancer Res Treat 32: 73-84, 1994.

6. Fidler IJ: Selection of successive tumor lines for metastasis. Nature New Biol 242: 148-149, 1973.

7. Fidler IJ, Gersten DM and Budmen MB: Characterization in vivo and in vitro of tumor cells selected for resistance to syngeneic lymphocyte-mediated cytotoxicity. Cancer Res 36: 3160-3165, 1976.

8. Briles EB and Kornfeld S: Isolation and metastatic properties of detachment variants of B 16 melanoma cells. J Natl Cancer Inst 60: $1217-1222,1978$

9. Kerbel RS, Twiddy RR and Robertson DM: Induction of a tumor with greatly increased metastatic growth potential by injection of cells from a low-metastatic $\mathrm{H}-2$ heterozygous tumor cell line into an $\mathrm{H}-2$ incompatible parental strain. Int $\mathrm{J}$ Cancer 22: $583-594,1978$

10. Suzuki $\mathrm{N}$ and Withers HR: Lung colony formation: a selective cloning progress for lung-colony-forming ability. Br J Cancer 39: 196-199, 1979.

11. Poste G, Doll J, Hart IR and Fidler IJ: In vitro selection of murine B16 melanoma variants with enhanced tissue-invasive properties. Cancer Res 40: 1636-1644, 1980.

12. Albercht-Bueler G: The phagokinetic track assay of 3T3 cells. Cell 11: 395-404, 1977.

13. Seyedin SM, Thompson AY, Bentz H, et al: Cartilage-inducing factor-A. J Biol Chem 261: 5693-5695, 1986.

14. Guise TA: Molecular mechanisms of osteolytic bone metastases. Cancer 88: 2892-2898, 2000.

15. Pfeilschifter J and Mundy G: Modulation of type $\beta$ transforming growth factor activity in bone cultures by osteotropic hormones. Proc Natl Acad Sci USA 84: 2024-2028, 1987.

16. Lin M and Golen KL: Rho-regulatory proteins in breast cancer cell motility and invasion. Breast Cancer Res Treat 84: 49-60, 2004.

17. Liotta LA, Tryggvason K, Garbisa S, Hart I, Foltz CM and Shafie S: Metastatic potential correlates with enzymatic degradation of basement membrane collagen. Nature 284: 67-68, 1980.

18. Duffy MJ, Maguire TM, Hill A, McDermott E and O'Higgins N: Metalloproteinases: role in breast carcinogenesis, invasion and metastasis. Breast Cancer Res 2: 252-257, 2000.

19. John A and Tuszynski G: The role of matrix metalloproteinases in tumor angiogenesis and tumor metastasis. Pathol Oncol Res 7: 14-23, 2001 .

20. Sternlicht MD and Werb Z: How matrix metalloproteinases regulate cell behavior. Ann Rev Cell Dev Biol 17: 463-516, 2001.

21. Stetler-Stevenson WG and Yu AE: Proteinases in invasion: matrix metalloproteinases. Semin Cancer Biol 11: 143-152, 2001.

22. Egeblad M and Werb Z: New functions for the matrix metalloproteinases in cancer progression. Nat Rev Cancer 2: 161-174, 2002.

23. Lochter A and Bissell M: An odyssey from breast to bone: Multi-step control of mammary metastases and osteolysis by matrix metalloproteinases. APMIS 107: 128-136, 1999.
24. Imai K, Hiramatsu A, Fukushima D, Pierschbacher MD and Okada Y: Degradation of decorin by matrix metalloproteinases: identification of the cleavage sites, kinetic analyses and transforming growth factor- $\$ 1$ release. J Biochem 322: 809-814, 1997.

25. English WR, Puente XS, Freije JMP, et al: Membrane Type 4 matrix metalloproteinase (MMP-17) has tumor necrosis factor- $\alpha$ convertase activity but does not activate pro-MMP2. J Biol Chem 275: 14046-14055, 2000.

26. Kang Y, Siegel PM, Shu W, et al: A multigenic program mediating breast cancer metastasis to bone. Cancer Cell 3: $537-549,2003$.

27. Iwata H, Kobayashi S, Iwase H, Masaoka A, Fujimoto N and Okada Y: Production of matrix metalloproteinases and tissue inhibitors of metalloproteinases in human breast carcinomas. Jpn J Cancer Res 87: 602-611, 1996.

28. Brummer O, Athar S, Riethdorf L, Loning T and Herbst $\mathrm{H}$ : Matrix-metalloproteinases 1,2 and 3 and their tissue inhibitors 1 and 2 in benign and malignant breast lesions: an in situ hybridization study. Virchows Arch 435: 566-573, 1999.

29. Remacle AG, Noel A, Duggan C, McDermott E, O'Higgins N, Foidart JM and Duffy MJ: Assay of matrix metalloproteinases types 1, 2, 3 and 9 in breast cancer. Br J Cancer 77: 926-931, 1988.

30. Nakopoulou L, Giannopoulou I, Gakiopoulou H, Liapis H, Tzonou A and Davaris P: Matrix metalloproteinase- 1 and -3 in breast cancer: correlation with progesterone receptors and other clinicopathologic features. Hum Pathol 30: 436-442, 1999.

31. Lhotak S, Elavathil LJ, Vukmirovic-Popovic S, Duivenvoorden WCM, Tozer RG and Singh G: Immuno-localization of matrix metalloproteinases and their inhibitors in clinical specimens of bone metastasis from breast carcinoma. Clin Exp Metastasis 18: 463-470, 2001

32. Mackie EJ: Osteoblasts: novel roles in orchestration of skeletal architecture. Int J Biochem Cell Biol 35: 1301-1305, 2003.

33. Kleinman HK, McGarvey ML, Hassell JR, Star VL, Cannon FB, Laurie GW and Martin GR: Basement membrane complexes with biological activity. Biochemistry 25: 312-318, 1986.

34. Kawamata H, Furihata T, Omotehara F, et al: Identification of genes differentially expressed in a newly isolated human metastasizing esophageal cancer cell line, T.Tn-AT1, by cDNA microarray. Cancer Sci 94: 699-706, 2003.

35. Farina AR, Tacconelli A, Cappabianca L, Gulino A and Mackay AR: Inhibition of human MDA-MB-231 breast cancer cell invasion by matrix metalloproteinase 3 involves degradation of plasminogen. Eur J Biochem 269: 4476-4483, 2002.

36. Eilon G and Mundy GR: Direct resorption of bone by human breast cancer cells in vitro. Nature 276: 726-728, 1978

37. Nemth JA, Yousif R, Herzog M, et al: Matrix metalloproteinase activity, bone matrix turnover and tumor cell proliferation in prostate cancer bone metastasis. J Natl Cancer Inst 94: 17-25, 2002.

38. Pederson L, Winding B, Foged NT, Spelsberg TC and Oursler MJ: Identification of breast cancer cell line-derived paracrine factors that stimulate osteoclast activity. Cancer Res 59: 5849-5855, 1999.

39. Tumber A, Morgan HM, Meikle MC and Hill PA: Human breastcancer cells stimulate the fusion, migration and resorptive activity of osteoclasts in bone explants. Int J Cancer 91: 665672,2001 .

40. Powell GJ, Southby J, Danks JA, et al: Localization of parathyroid hormone-related protein in breast cancer metastases: increased incidence in bone compared with other sites. Cancer Res 51: 3059-3061, 1991

41. Gallwitz WE, Guise TA and Mundy GR: Guanosine nucleotides inhibit different syndromes of PTH-rP excess caused by human cancers in vivo. J Clin Invest 110: 1559-1572, 2002.

42. Sanchez-Sweatman OH, Lee J, Orr FW and Singh G: Directly osteolysis induced by metastatic murine melanoma cells: role of matrix metalloproteinases. Eur J Cancer 33: 918-925, 1997. 